\title{
The Key Role of VEGF in the Cross Talk between Pterygium and Dry Eye and Its Clinical Significance
}

\author{
Chang Liu Yiyue Song Xiaoran Wang Zhaoguang Lai Chaoyang Li \\ Pengxia Wan NuoXu Danping Huang Yizhi Liu Zhichong Wang \\ State Key Laboratory of Ophthalmology, Zhongshan Ophthalmic Center, Sun Yat-sen University, Guangzhou, China
}

\section{Keywords}

Pterygium · Dry eye · VEGF · Cytokines · Inflammation

\begin{abstract}
Purpose: To examine whether dry eye severity is a risk factor for pterygium activity and whether vascular endothelial growth factor (VEGF) is crucial in the cross talk between pterygium and dry eye. Methods: A total of 103 patients with primary pterygium (Pteg) were included in the study group; they were divided into 2 groups according to the complication of dry eye (DE) (Pteg + DE group, Pteg - DE group). Further, 60 patients with just dry eye (DE group) and 60 normal individuals (normal) were included as 2 control groups. DE severity and pterygium activity were measured, and unstimulated tear samples and pterygium tissues were collected for cytokine detection. Results: (1) Tear detection: VEGF expression increased in the Pteg + DE group compared to the Pteg - DE, DE, and normal control groups; VEGF was especially increased in the active Pteg + DE group. VEGF concentration was positively correlated with pterygium activity. (2) Tissue detection: the mRNA expression of VEGF was upregulated in the active pterygium group. Conclusions: Inflammation played an important role in the development of dry eye
\end{abstract}

and pterygium. VEGF was the core molecule in the cross talk, which might explain the high incidence of the coexistence of these 2 diseases.

(c) 2020 The Author(s)

Published by S. Karger AG, Basel

\section{Introduction}

Pterygium and dry eye are both common ocular surface diseases, and pterygium is listed as a dry eye-related factor [1]. The occurrence of pterygium can shorten the tear break-up time (TBUT) of the affected eye and create an unstable tear film; this might be caused by changes in ocular surface regularity as a result of pterygium [2]. However, one study found that the ocular surface tear film stability of patients with pterygium was not different from that of normal individuals [3]. What are the reasons for these contradictory study findings? A recent study indicated that pterygium recurrence is associated with a greater severity of dry eye, possibly by perpetuating ocular surface inflammation in the postoperative period [4].

Y.L. and Z.W. contributed equally to this work and should be considered co-corresponding authors.

$\begin{array}{ll}\text { karger@karger.com } & \text { (c) 2020 The Author(s) } \\ \text { Published by S. Karger AG, Basel } & \text { Karger } \\ \text { Thw.karger.com/ore } & \text { This article is licensed under the Creative Commons Attribution- } \\ \text { NonCommercial-NoDerivatives 4.0 International License (CC BY- } \\ \text { NC-ND) (http://www.karger.com/Services/OpenAccessLicense). } \\ \text { Usage and distribution for commercial purposes as well as any dis- } \\ \text { tribution of modified material requires written permission. }\end{array}$

Yizhi Liu, MD, PhD, and Zhichong Wang, MD, PhD

State Key Laboratory of Ophthalmology

Zhongshan Ophthalmic Center, Sun Yat-sen University

54 S. Xianlie Road, Guangzhou, Guangdong 510060 (China)

E-Mail liuyizhi@gzzoc.com and wangzhichong@gzzoc.com 
The present preliminary clinical study showed that progressive and inactive pterygium exhibited different dry eye signs, indicating the close association between pterygium and dry eye.

Although there are several studies that have examined the association between pterygium and dry eye, many studies that only targeted pterygium or dry eye suggested that inflammatory mechanisms may be involved in the development of both conditions and influence the inflammation regulatory pathways through the highly overlapped relevant inflammatory factors [5-9]. The core factors involved in chronic immune inflammation in dry eye have been recognized and studied in depth [5]. The ocular surface tissues of dry eye patients have a large amount of $\mathrm{CD}^{+} \mathrm{T}$ cell infiltration [10]. Several cytokines and inflammatory mediators, including interleukin- $1 \beta$ (IL-1 $\beta$ ), IL-2, IL-4, IL-5, IL-6, IL- 8 , interferon- $\gamma$, tumor necrosis factor- $\alpha$ (TNF- $\alpha$ ), and matrix metalloproteinase-9 (MMP-9), also play important roles [11]. These factors make up a vicious chronic inflammatory cycle that involves both innate immunity and adaptive immunity resulting from $\mathrm{T}$ cell-mediated immune activity. In particular, Th17 cell-mediated adaptive immunity is considered to play an important role in inflammation in dry eye. Recent studies on pterygium had similar findings $[9,12]$. Pterygium is a progressive tissue growth featuring a large amount of lymphocyte and mononuclear macrophage infiltration, especially with massive $\mathrm{CD} 4^{+} \mathrm{T}$ cell infiltration and increased IL-1, IL-6, and IL-8 expression [9]. Huang et al. [12] reported that the ocular surface tissues of pterygium patients expressed high levels of IL-17, suggesting that pterygium was a chronic inflammatory disorder similar to the chronic inflammation in dry eye; it involved both innate immunity and adaptive immunity as well as autoimmunity mediated by Th17 cells.

In 2007, the Dry Eye Workshop (DEWS) proposed that increased tear osmolarity and ocular surface inflammation were the core pathogenic mechanisms of dry eye [13]. Increased tear osmolarity activates the mitogen-activated protein kinase/nuclear factor- $\kappa \mathrm{B}$ (MAPK/NF- $\kappa \mathrm{B})$ signaling pathway in ocular surface epithelial cells to produce a series of inflammatory cytokines (TNF- $\alpha$, IL-6, IL10, and IL-11), chemokines (monocyte chemoattractant protein-1, IL-8, and RANTES), and MMPs. These inflammatory cascade reactions directly or indirectly cause the apoptosis of ocular surface cells, disrupting the accessory lacrimal gland (which is responsible for the basal secretion of tears) and the goblet cells (which secrete mucin); this can result in dry eye. Similarly, recent studies by Ozsutcu et al. [14] showed that tear osmolarity was higher in pterygium patients than in normal individuals, suggesting that pterygium also involves the pathological phenomenon of increased tear osmolarity, which might result in chronic inflammatory cascade reactions. As early as 1989, Hill and Maske [15] proposed that chronic noninfectious inflammation might be the pathogenic mechanism of pterygium. Subsequent studies [16, 17] have shown that the onset of pterygium is associated with midultraviolet $B$ (UVB); UVB radiation activates the NF- $\kappa B$ transcription factor in epithelial cells [18] to upregulate the expression of inflammatory proteins such as IL-6 and IL-8 [6]. Another study indicated that the key feature of pterygium is focal limbal failure and centripetal invasion of the cornea via altered limbal epithelial cells, which display squamous metaplasia and goblet cell hyperplasia [19]. This is accompanied by a breakdown of Bowman's layer and a stromal overgrowth of activated fibroblasts, inflammatory cell infiltrate, neovascularization, abnormal extracellular matrix accumulation, and elastosis. Furthermore, the expression levels of MMP-1, MMP-3, and MMP-9 are high in patients with pterygium [20], so these factors are considered to be associated with promoting the infiltration of pterygium tissues toward a transparent cornea [21]; they are also thought to be involved in the pathological processes of pterygium development and postoperative recurrence.

Vascular endothelial growth factor (VEGF) and basic fibroblast growth factor (bFGF) are highly expressed in pterygium tissues and can promote the differentiation, proliferation, and migration of vascular endothelial cells and fibroblasts [22,23]. VEGF can also increase the permeability of vascular endothelial cells and participate in the pathological process of chronic inflammation [22]. Therefore, inflammation is involved at the onset and progression of both pterygium and dry eye. The other key factors in the pathogenic mechanism of these 2 diseases, ultraviolet (UV) radiation-induced stress and tear hyperosmolarity, are 2 major stimulation factors targeting the NF- $\mathrm{kB}$ signaling pathway [24]. Thus, attention should be paid to cytokines such as MMPs, IL-6, IL-8, and VEGF, which are related to the activation of the NF- $\kappa$ B signaling pathway.

Pterygium and damage to the conjunctival goblet cells that secret ocular surface mucin usually occur at the same time [2], suggesting that the elucidation of the pathogenic mechanisms and pathogenic factors of the coexistence of these 2 diseases may help to guide clinical treatment. Therefore, this study examines proinflammatory markers (IL-6 and IL-8), matrix metalloproteinases (MMP-1 and MMP-9), and growth factors (VEGF and bFGF) in eyes with different statuses of pterygium and dry eye. 


\section{Materials and Methods}

\section{Subjects and Clinical Tests}

This study involved 103 eyes with primary nasal pterygium from patients treated in Zhongshan Ophthalmic Center, Sun Yatsen University, during 2015-2017. Furthermore, 103 pterygium patients were assessed and divided into the pterygium without dry eye group (Pteg - DE group, 27 eyes) and pterygium with dry eye group (Pteg + DE group, 76 eyes) according to whether the affected eyes were combined with dry eye. Patients with StevensJohnson syndrome and Sjögren Syndrome were excluded from the research. Within 1 week of data collection, all of the pterygium patients received simple pterygium resection by the same surgeon. As control, 60 eyes from dry eye patients and 60 eyes from normal individuals were recruited. The Ethics Committee of Zhongshan Ophthalmic Center, Sun Yat-sen University, approved this crosssectional study; it conformed to the ethical guidelines of the Helsinki Declaration. All of the experimental subjects filled out an informed consent form before participating in the study.

The same experienced doctor performed clinical examinations using a prearranged sequence as follows: (1) ocular surface disease index (OSDI) questionnaire [25], (2) tear collection, (3) slit lamp examination, (4) TBUT (measured following the instillation of $5-10 \mu \mathrm{L}$ of $1 \%$ fluorescein dye [26] with the mean of the 3 measurements recorded), (5) corneal fluorescent (FL) staining scoring graded based on the Oxford scoring scheme, and (6) Schirmer's test (ST) using strips of Whatman 41 filter paper (Tianjin Jingming New Technology Development Co., Ltd., Tianjin, China) [27]; the length of wetting was recorded after $5 \mathrm{~min}$. Pterygium was diagnosed if a characteristic raised fleshy growth crossing the corneoscleral limbus and encroaching on the clear cornea was present [28]; disease course and the length of the pterygium invading the limbus were recorded. According to the morphological classification of pterygium [29], pterygium activity was classified into 3 grades: Pteg1, Pteg2, and Pteg3 (Table 1). The dry eye diagnostic criteria included the following subjective symptoms: drying, foreign body, burning, fatigue, malaise, and vision fluctuations with TBUT $\leq 5 \mathrm{~s}$ or SIt $\leq 5 \mathrm{~mm} / 5 \mathrm{~min}$, or one of the above subjective symptoms with $5 \mathrm{~s}<$ TBUT $\leq 10 \mathrm{~s}$ or SIt $>5 \mathrm{~mm} / 5 \mathrm{~min}$ plus the combined positive FL. According to the DEWS diagnostic classification criteria [30], dry eye severity was classified into 4 grades (Table 2).

\section{Tear Collection and Tear Cytokine Analyses}

The unstimulated tear samples were collected with disposable $2 \mu \mathrm{L}$ microcapillaries (Microcap $2 \mu \mathrm{L}$; Drummond Scientific, Broomall, PA, USA). The tears were gathered from the inferior meniscus of each eye, obtaining $6 \mu \mathrm{L}$ of tears. The tears were immediately stored at $-80^{\circ} \mathrm{C}$ until analysis. The concentrations of the cytokines (IL-6, IL-8, MMP-1, MMP-9, VEGF, and bFGF) were determined by multiplex bead technology with commercially available kits (Milliplex MAP; Millipore, Billerica, MA, USA).

\section{Pterygium Cytokine Gene Expression}

Total RNA was extracted from each pterygium tissue using TRIzol (Invitrogen Life Technologies, Grand Island, NY, USA); then, the RNA was reverse transcribed with the Takara First Strand Synthesis kit (TaKaRa, Dalian, China). Real-time quantitative PCR was run on an ABI Prism 7000 system with SYBR Green PCR kit (TaKaRa, Dalian, China). PCR was performed by denaturing at
Table 1. Clinical characteristics of pterygium patients

\begin{tabular}{lll}
\hline & Pteg - DE & Pteg + DE \\
\hline Course of disease, years $^{\mathrm{a}}$ & $7.30 \pm 4.46(2-20)$ & $7.89 \pm 4.58(2-25)$ \\
LPICL, mm $^{\mathrm{b}}$ & $3.11 \pm 0.76$ & $3.33 \pm 0.95$ \\
Pterygium activity grading $^{\mathrm{c}}$ & & \\
1 & $13(48.15)$ & $15(36.74)$ \\
2 & $12(44.44)$ & $33(43.42)$ \\
3 & $2(7.41)$ & $28(36.84)$ \\
\hline
\end{tabular}

Data are presented as mean \pm SD (range) or patient number (\%). LPICL, length of pterygium invaded into corneal limbus.

a There was no statistical significance between the pterygium with dry eye group (Pteg + DE) $7.89 \pm 4.58$ and without dry eye group (Pteg - DE), $7.30 \pm 4.46$.

$\mathrm{b}$ There was no statistical significance between the pterygium with dry eye group (Pteg + DE) $3.33 \pm 0.95$ and without dry eye group (Pteg - DE), $3.11 \pm 0.76$.

${ }^{c}$ The proportion of pterygium activity grades was statistically different between these 2 groups $\left({ }^{* *} p<0.01\right)$.

Table 2. Grades of dry eye severity

\begin{tabular}{|c|c|c|c|c|}
\hline & \multicolumn{4}{|l|}{ Grade } \\
\hline & 1 & 2 & 3 & 4 \\
\hline OSDI scoring & $12-15$ & $16-30$ & $31-45$ & $>45$ \\
\hline TBUT, s & $8-15$ & $<10$ & $<5$ & $\begin{array}{l}\text { immedi- } \\
\text { ately }\end{array}$ \\
\hline Schirmer's test, $\mathrm{mm} / 5 \mathrm{~min}$ & $<10-15$ & $<10$ & $<5$ & $<2$ \\
\hline Corneal FL staining scoring & $0-3$ & $1-8$ & $9-14$ & $14-15$ \\
\hline
\end{tabular}

OSDI, ocular surface disease index; TBUT, tear break-up time; FL, fluorescent.

$95^{\circ} \mathrm{C}$ for $5 \mathrm{~min}$, followed by 40 cycles of denaturation at $95^{\circ} \mathrm{C}$, annealing at $60^{\circ} \mathrm{C}$, and extension at $72^{\circ} \mathrm{C}$ for $10 \mathrm{~s}$, respectively.

\section{Statistical Analysis}

The dry eye and normal control groups both used the mean values of the left and right eyes. Age, OSDI, and cytokine concentrations were compared among multiple groups using unifactorial analysis of variance. Mean values were compared between multiple samples using the Tukey and Bonferroni methods. Gender comparisons were performed using the $\chi^{2}$ test. Grades of pterygium activity, corneal encroachment of the pterygium, and cytokine concentrations in tears between 2 groups were compared using the Kruskal-Wallis test. The comparison between multiple groups was performed using the Mann-Whitney $U$ test. Correlation analysis and logistic regression were performed to explore the risk factors of dry eye in patients with different pterygium activity. $p<0.05$ indicates statistical significance. SPSS 16.0 statistical software was used for data analyses. In the paper, data are shown as mean \pm SD. All values are shown as mean \pm SE in statistic figures. 
Table 3. Patient demographic information

\begin{tabular}{|c|c|c|c|c|}
\hline Primary pterygium & Total & Pteg + DE & Pteg - DE & $p$ value \\
\hline Number of eyes & 103 & 76 & 27 & \\
\hline Sex, M:F (female \%) & $32: 71(69)$ & $22: 54(71)$ & $10: 17(63)$ & $>0.05$ \\
\hline \multicolumn{5}{|l|}{ Age, years } \\
\hline Mean \pm SD & $55.9 \pm 9.0$ & $55.1 \pm 8.8$ & $55.8 \pm 9.4$ & $>0.05$ \\
\hline Range & $36-73$ & $36-70$ & $39-73$ & \\
\hline \multicolumn{5}{|l|}{ Duration, years } \\
\hline Mean \pm SD & $7.74 \pm 4.51$ & $7.30 \pm 4.46$ & $7.89 \pm 4.58$ & $>0.05$ \\
\hline Range & $2-25$ & $2-20$ & $2-25$ & \\
\hline \multicolumn{5}{|l|}{ LPICL, mm } \\
\hline Mean \pm SD & $3.27 \pm 0.90$ & $3.33 \pm 0.95$ & $3.11 \pm 0.76$ & $>0.05$ \\
\hline Activity grading, 1:2:3 & $28: 45: 30$ & $15: 33: 28$ & $13: 12: 2$ & $<0.01^{* *}$ \\
\hline
\end{tabular}

\section{Results}

\section{Patient Demographic Information}

This study involved 103 pterygium patients (mean age \pm SD $55.9 \pm 9.0$ years; age range $36-73$; female: $69.3 \%$ ), 60 eyes from dry eye patients (mean age \pm SD $55.5 \pm 8.5$ years; age range $38-72$ : female: $60 \%$ ), and 60 eyes from normal individuals (mean age \pm SD $54.1 \pm 9.5$ years, age range $37-70$; female: $60 \%$ ).

One hundred and three pterygium patients were assessed and divided into the pterygium without dry eye group (Pteg - DE, 27 eyes) and pterygium with dry eye group (Pteg + DE, 76 eyes).

Patient demographic information was analyzed and classified in detail (Table 3).

\section{Clinical Assessment}

A total of 76 (73.8\%) out of the 103 primary pterygium patients reported dry eye. OSDI scores (Fig. 1): in the DE group $(26.60 \pm 9.60)$ and the Pteg + DE group $(24.18 \pm$ $11.02)$, the scores increased significantly compared to the normal control group $(6.16 \pm 4.42)$ and the Pteg - DE group $(7.31 \pm 6.00 ; p<0.0001)$. TBUT (Fig. 1): in the DE group (4.15 \pm 1.61$)$ and the Pteg + DE group (4.22 \pm 1.9$)$, TBUT was significantly shortened compared to the normal control group $(9.52 \pm 1.61)$ and the Pteg $-\mathrm{DE}$ group $(8.69 \pm 2.34 ; p<0.0001)$. FL scores (Fig. 1$)$ : in the DE group (1.60 \pm 1.25$)$ and the Pteg + DE group (2.12 \pm 1.67$)$, the scores increased significantly compared to the normal control group $(0.33 \pm 0.48)$ and the Pteg $-\mathrm{DE}$ group $(0.37$ $\pm 0.63 ; p<0.0001)$. ST (Fig. 1$)$ : in the DE group (3.63 \pm $1.58)$ and the Pteg + DE group $(3.88 \pm 1.96)$, ST decreased significantly compared to the normal control group (8.54

The Key Role of VEGF in Cross Talk

between Pterygium and Dry Eye $\pm 1.73)$ and the Pteg - DE group $(7.61 \pm 2.44 ; p<0.0001)$. The mean course of pterygium and the mean length of pterygium across the limbus were not significantly different between the Pteg + DE and Pteg - DE groups, nor was the pterygium activity grade statistically significant.

Correlation analysis was performed to explore the severity of dry eye and the pterygium-related damage factors (pterygium mean course, pterygium activity grade, and mean length of pterygium across the limbus). The results showed that most patients had mild-moderate dry eye (grade 1: 6 eyes, $7.89 \%$; grade 2: 30 eyes, $39.47 \%$; grade 3: 37 eyes, $48.6 \%$; grade $4: 3$ eyes, 3.95\%). Severity of dry eye positively correlated with pterygium disease course $(r=0.257, p<0.05)$ and pterygium activity grade $(r=$ $0.345, p<0.01)$; however, the correlation coefficient with the length of pterygium across the limbus was not statistically significant $(r=0.136, p>0.05)$. The logistic regression model was further applied using pterygium disease course and pterygium activity grade as indictors to screen for risk factors that could predict the severity of dry eye in pterygium patients. According to the results of the likelihood ratio tests, the effect of disease course on the regression was not statistically significant ( $p=0.83$ ); therefore, it was not included in the equation. The pterygium activity grade was a significant factor for predicting the severity of dry eye in pterygium patients (B: partial regression coefficient $=-3.384$; $\mathrm{StD} \mathrm{B}$ : standard partial regression coefficient $=0.662 ; p<0.0001$ ). Regarding the pterygium activity grade using grade 1 as a reference, grade 2 and 3 had similar effects on the severity of dry eye; further, the differences of the latter 2 grades from grade 1 were statistically significant (grade $2: p<0.01$; grade 3 : $p<0.001)$. However, when using grade 2 as a reference, 
Fig. 1. Bar graphs showing the comparison of clinical indicators between the Pteg $+\mathrm{DE}$ group $(n=76)$, Pteg - DE group $(n=27)$, DE group $(n=30)$, and normal group $(n=$ 30). Age, OSDI, and cytokine concentrations were compared among multiple groups using unifactorial analysis of variance. Mean values were compared between multiple samples using the Bonferroni method. All values are shown as mean \pm SE. **** $p<0.0001$.
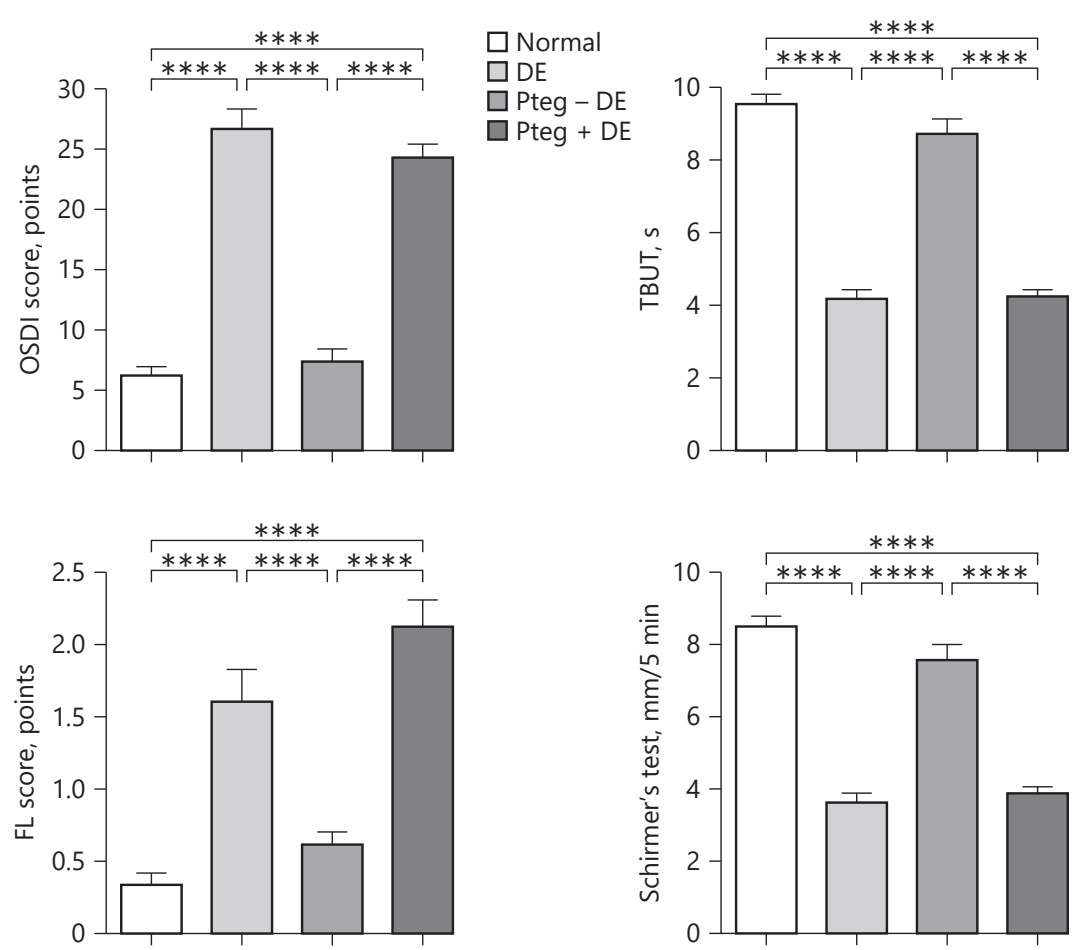

the effects of grade 3 on the severity of dry eye were not different $(p=0.158)$. Based on the above findings, in the subsequent analysis, cytokines combining grade 2 and 3 pterygium activity were combined into 1 group: the active pterygium group (active Pteg). Grade 1 pterygium was named the inactive pterygium group (inactive Pteg).

\section{Tear Inflammatory Cytokine Assessment}

Tear IL-6 concentration was significantly higher in the Pteg + DE group $(335.69 \pm 141.01 \mathrm{pg} / \mathrm{mL})$, the Pteg $-\mathrm{DE}$ group $(220.79 \pm 131.48 \mathrm{pg} / \mathrm{mL})$, and the DE group (294.47 $\pm 197.74 \mathrm{pg} / \mathrm{mL})$ than in the normal control group (93.39 $\pm 43.37 \mathrm{pg} / \mathrm{mL}$ ). The concentration in the Pteg $+\mathrm{DE}$ group $(335.69 \pm 141.01 \mathrm{pg} / \mathrm{mL})$ was significantly higher than that in the Pteg - DE group $(220.79 \pm 131.48 \mathrm{pg} / \mathrm{mL}$; $p<0.001$; Fig. 2).

Tear IL- 8 concentration was significantly higher in the Pteg + DE group $(3,958.31 \pm 1,641.04 \mathrm{pg} / \mathrm{mL})$, the Pteg DE group $(3,058.00 \pm 1,612.06 \mathrm{pg} / \mathrm{mL})$, and the $\mathrm{DE}$ group $(3,414.80 \pm 1,564.69 \mathrm{pg} / \mathrm{mL})$ than in the normal control group $(1,163.69 \pm 550.04 \mathrm{pg} / \mathrm{mL} ; p<0.001)$. The concentration in the Pteg + DE group $(3,958.31 \pm 1,641.04 \mathrm{pg} /$ $\mathrm{mL}$ ) was significantly higher than that in the Pteg - DE group $(3,058.00 \pm 1,612.06 \mathrm{pg} / \mathrm{mL} ; p<0.01$; Fig. 2$)$.
Tear VEGF concentration significantly increased in the Pteg + DE group $(1,914.31 \pm 912.81 \mathrm{pg} / \mathrm{mL})$ compared to the Pteg - DE group $(916.00 \pm 442.88 \mathrm{pg} / \mathrm{mL})$, DE group $(1,264.64 \pm 576.93 \mathrm{pg} / \mathrm{mL})$, and normal control group $(742.30 \pm 318.02 \mathrm{pg} / \mathrm{mL} ; p<0.001)$. The concentration in the DE group $(1,264.64 \pm 576.93 \mathrm{pg} / \mathrm{mL})$ was higher than in the normal control group $(742.30 \pm 318.02 \mathrm{pg} /$ $\mathrm{mL} ; p<0.001$; Fig. 2).

Tear bFGF concentration was higher in the Pteg $+\mathrm{DE}$ group $(220.59 \pm 90.63 \mathrm{pg} / \mathrm{mL})$ and the Pteg $-\mathrm{DE}$ group $(204.55 \pm 96.55 \mathrm{pg} / \mathrm{mL})$ than in the normal control group $(113.85 \pm 53.12 \mathrm{pg} / \mathrm{mL})$ and the DE group $(87.18 \pm 90.46$ $\mathrm{pg} / \mathrm{mL} ; p<0.001$; Fig. 2).

Tear MMP-1 concentration was significantly higher in the Pteg + DE group $(357.60 \pm 186.33 \mathrm{pg} / \mathrm{mL})$ and the Pteg - DE group $(259.59 \pm 140.51 \mathrm{pg} / \mathrm{mL})$ than in the normal control group $(118.77 \pm 73.85 \mathrm{pg} / \mathrm{mL} ; p<0.0001)$. The concentration in the Pteg + DE group (357.60 \pm $186.33 \mathrm{pg} / \mathrm{mL}$ ) was higher than in the DE group (206.19 $\pm 150.41 \mathrm{pg} / \mathrm{mL} ; p<0.001$; Fig. 2).

Tear MMP-9 concentration was higher in the Pteg + DE group $(34,822.57 \pm 17,790.94 \mathrm{pg} / \mathrm{mL})$, the Pteg $-\mathrm{DE}$ group $(21,591.23 \pm 11,489.96 \mathrm{pg} / \mathrm{mL})$, and the $\mathrm{DE}$ group $(19,341.02 \pm 12,381.92 \mathrm{pg} / \mathrm{mL})$ than in the normal control 
Fig. 2. Bar graphs showing the comparison of tear cytokine concentration between the Pteg + DE group $(n=76)$, Pteg - DE group $(n=27)$, DE group $(n=60)$, and normal group $(n=60)$. Cytokine concentrations in tears were compared between 2 groups using the Kruskal-Wallis test. The comparison among multiple groups was performed using the Mann-Whitney $U$ test. All values are shown as mean \pm SE. ${ }^{* *} p<0.01$; *** $p<0.001$; **** $p<0.0001$.
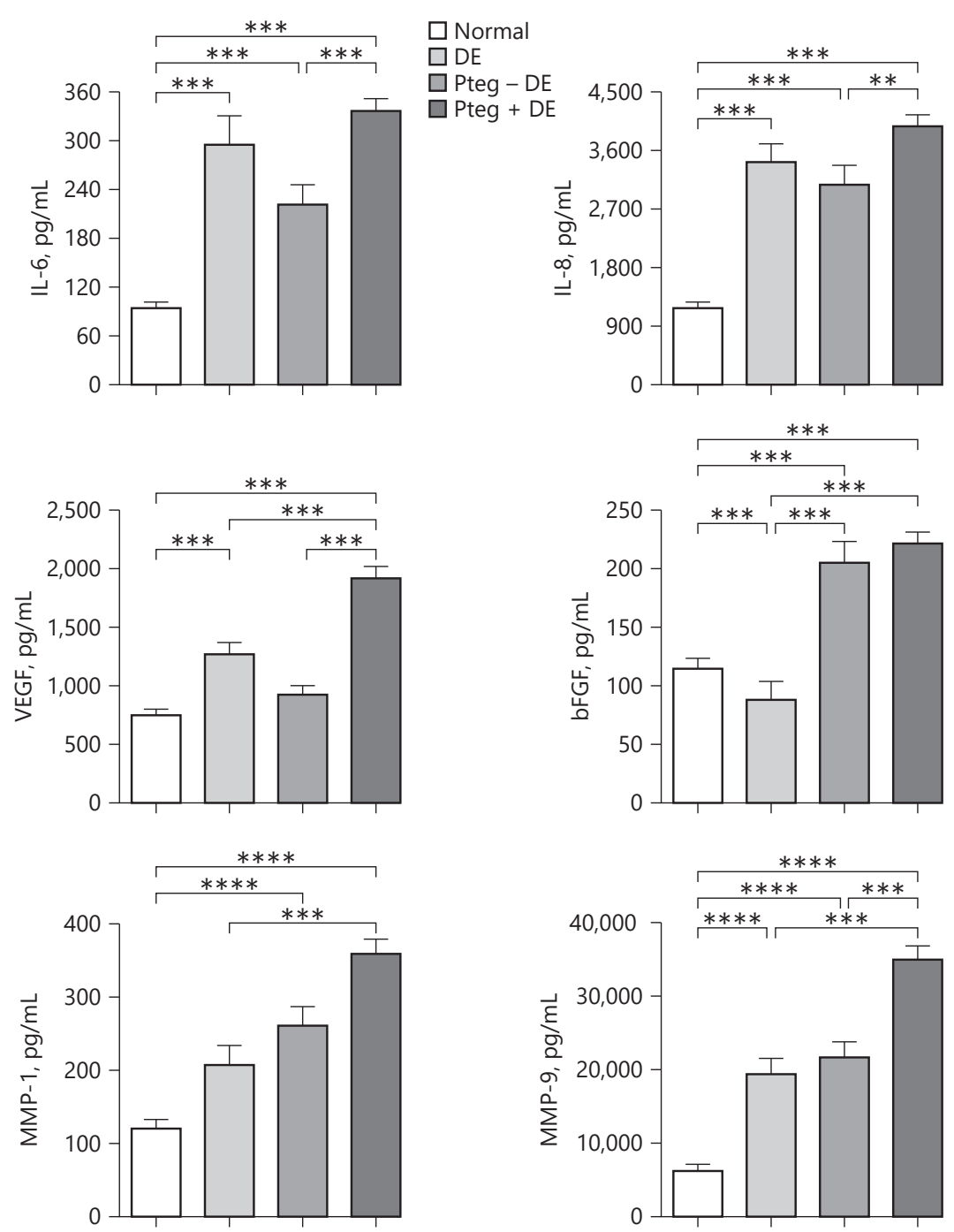

group $(6281.42 \pm 4748.90 \mathrm{pg} / \mathrm{mL} ; p<0.0001)$. The concentration in the Pteg + DE group $(34,822.57 \pm 17,790.94$ $\mathrm{pg} / \mathrm{mL}$ ) was significantly higher than in the Pteg - DE group $(21,591.23 \pm 11,489.96 \mathrm{pg} / \mathrm{mL})$ and the DE group $(19,341.02 \pm 12,381.92$ pg/mL; $p<0.001$; Fig. 2).

Tear IL- 6 concentration was significantly higher in the active Pteg group $(323.16 \pm 146.92 \mathrm{pg} / \mathrm{mL})$, the inactive Pteg group $(258.46 \pm 138.91 \mathrm{pg} / \mathrm{mL})$, and the $\mathrm{DE}$ group $(294.47 \pm 197.74 \mathrm{pg} / \mathrm{mL})$ than in the normal control group (93.39 $\pm 43.37 \mathrm{pg} / \mathrm{mL}$; $p<0.001$; Fig. 3 ).

Tear IL-8 concentration was significantly higher in the active Pteg group $(4,019.10 \pm 1,617.19 \mathrm{pg} / \mathrm{mL})$, the inactive Pteg group $(2,927.20 \pm 1,585.22 \mathrm{pg} / \mathrm{mL})$, and the $\mathrm{DE}$ group $(3,414.80 \pm 1,564.69 \mathrm{pg} / \mathrm{mL})$ than in the normal control group $(1,163.69 \pm 550.04 \mathrm{pg} / \mathrm{mL} ; p<0.001$; Fig. 3$)$. The concentration in the active Pteg group $(4,019.10 \pm$ $1,617.19 \mathrm{pg} / \mathrm{mL}$ ) was higher than in the inactive Pteg group $(2,927.20 \pm 1,585.22 \mathrm{pg} / \mathrm{mL} ; p<0.01$; Fig. 3$)$.

Tear VEGF concentration significantly increased in the active Pteg group $(1,894.60 \pm 895.07 \mathrm{pg} / \mathrm{mL})$ compared to the inactive Pteg group $(1,004.40 \pm 666.70 \mathrm{pg} /$ $\mathrm{mL})$, the DE group $(1,264.64 \pm 576.93 \mathrm{pg} / \mathrm{mL})$, and the normal control group $(742.30 \pm 318.02 \mathrm{pg} / \mathrm{mL} ; p<0.001$; Fig. 3).

The tear bFGF concentration was significantly higher in the active Pteg group $(232.53 \pm 91.18 \mathrm{pg} / \mathrm{mL})$ than in 
Fig. 3. Bar graphs showing the comparison of tear cytokine concentration between the active Pteg group $(n=75)$, inactive Pteg group $(n=28)$, DE group $(n=30)$, and normal group $(n=30$; subgroup analysis of the same data presented in Fig. 2). Cytokine concentrations in tears were compared between 2 groups using the Kruskal-Wallis test. All values are shown as mean \pm SE. ${ }^{* *} p<0.01$; ${ }^{* * *} p<0.001 ;{ }^{* * * *} p<0.0001$.
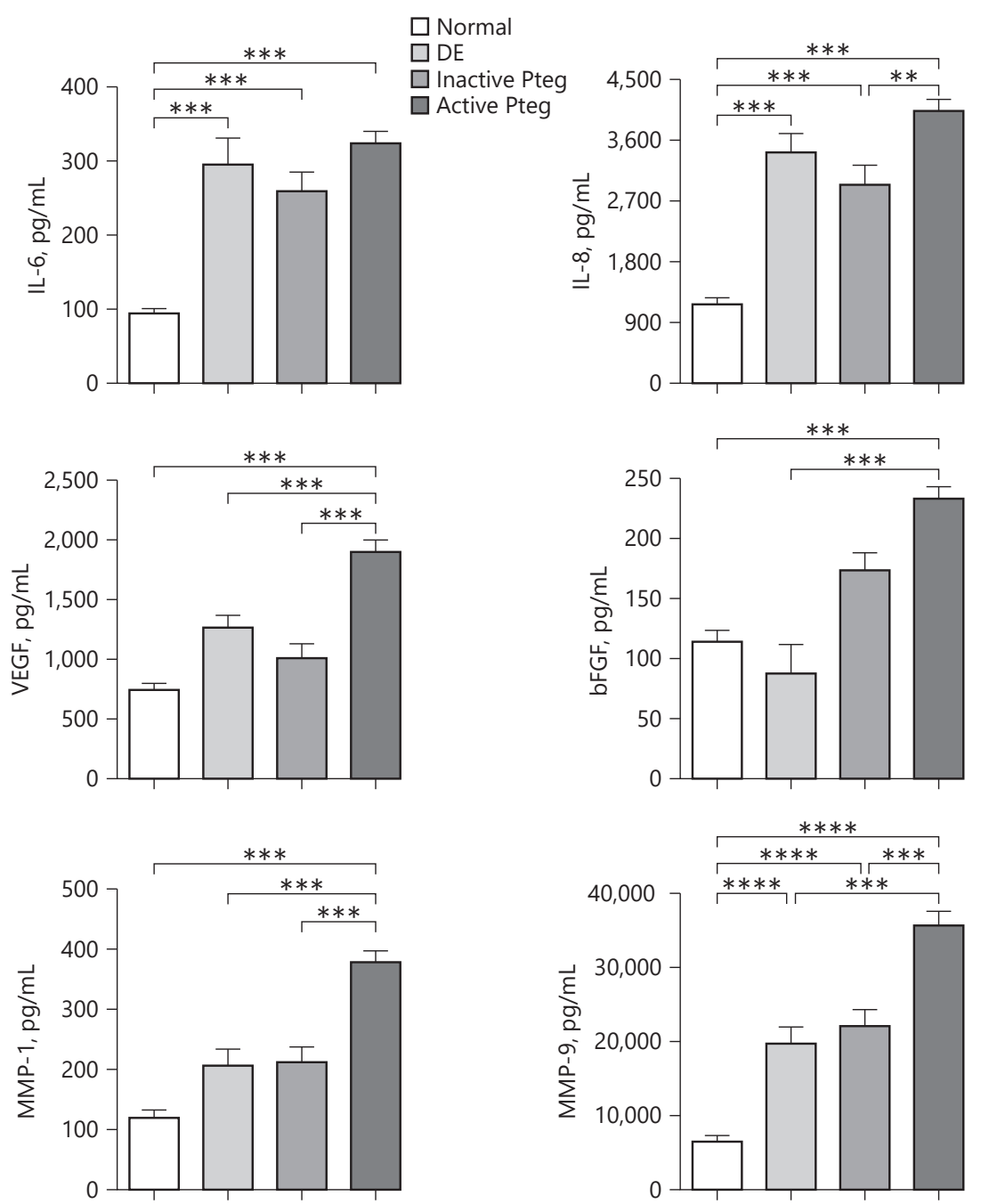

the DE group $(87.18 \pm 90.46 \mathrm{pg} / \mathrm{mL})$ and the normal control group (113.85 $\pm 53.12 \mathrm{pg} / \mathrm{mL} ; p<0.001$; Fig. 3 ).

Tear MMP-1 concentration significantly increased in the active Pteg group $(376.71 \pm 174.75 \mathrm{pg} / \mathrm{mL})$ compared to the inactive Pteg group $(211.88 \pm 135.40 \mathrm{pg} / \mathrm{mL})$, the DE group $(206.19 \pm 150.41 \mathrm{pg} / \mathrm{mL})$, and the normal control group (118.77 $\pm 73.85 \mathrm{pg} / \mathrm{mL} ; p<0.001$; Fig. 3 ).

Tear MMP-9 concentrations in the active Pteg group $(34,981.57 \pm 17,625.55 \mathrm{pg} / \mathrm{mL})$, the inactive Pteg group $(21,639.23 \pm 12,233.92 \mathrm{pg} / \mathrm{mL})$, and the $\mathrm{DE}$ group $(19,341.02 \pm 12,381.92 \mathrm{pg} / \mathrm{mL})$ were all higher than in the normal control group $(6,281.42 \pm 4,748.900 \mathrm{pg} / \mathrm{mL} ; p<$ 0.0001 ; Fig. 3$)$. The concentration in the active Pteg group $(34,981.57 \pm 17,625.55 \mathrm{pg} / \mathrm{mL})$ was higher than in the in- active Pteg group $(21,639.23 \pm 12,233.92 \mathrm{pg} / \mathrm{mL})$ and the DE group $(19,341.02 \pm 12,381.92 \mathrm{pg} / \mathrm{mL} ; p<0.001$; Fig. 3$)$.

Among the active Pteg patients, the expression levels of tear IL-6 (341.46 $\pm 139.41 \mathrm{pg} / \mathrm{mL})$, VEGF $(2,057.10 \pm$ $897.41 \mathrm{pg} / \mathrm{mL})$, and MMP-9 (37,637.43 $\pm 17,784.05 \mathrm{pg} /$ $\mathrm{mL}$ ) in patients who also had dry eye were significantly higher than the expression levels of tear IL-6 (243.40 \pm $157.35 \mathrm{pg} / \mathrm{mL})$, VEGF $(1,186.82 \pm 424.46 \mathrm{pg} / \mathrm{mL})$, and MMP-9 $(23,407.12 \pm 11,458.01 \mathrm{pg} / \mathrm{mL})$ in the patients without dry eye ( $p<0.01$; Fig. 4$)$.

\section{Pterygium Tissue Inflammatory Cytokine Assessment}

A comparison between the active + DE Pteg group and active - DE Pteg group with the inactive Pteg group as 
Fig. 4. Bar graphs showing the comparison of tear cytokine concentration between the active Pteg + DE group $(n=61)$ and the active Pteg - DE group ( $n=14$; subgroup analysis of the same data presented in Fig. 2). Cytokine concentrations in tears were compared between 2 groups using the Kruskal-Wallis test. All values are shown as mean \pm SE. ${ }^{* *} p<0.01$.
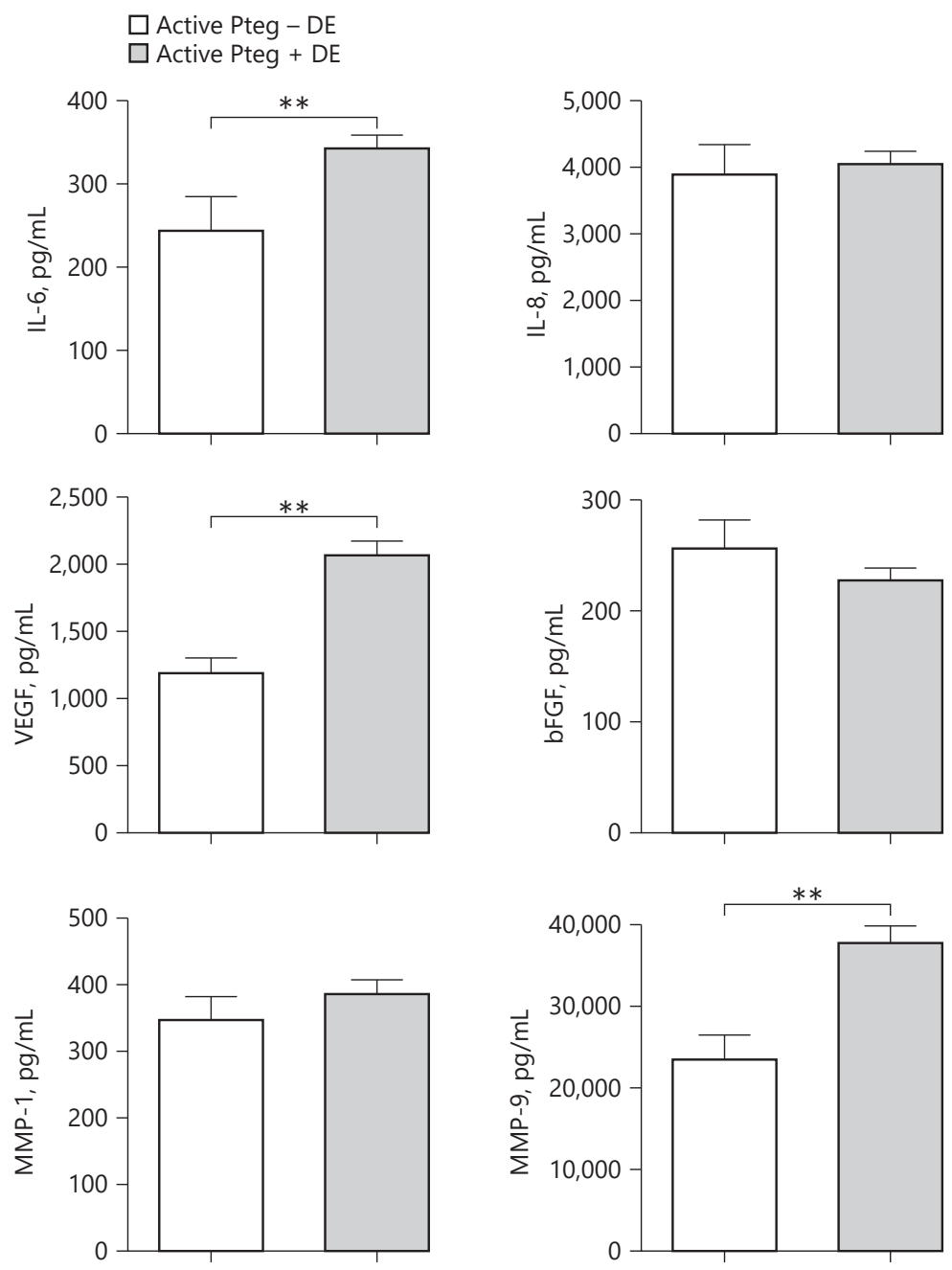

control showed that VEGF mRNA expression in the active - DE group was upregulated 1.4125-fold versus inactive pterygium ( $p<0.05$; Fig. 5 ), and VEGF mRNA expression in active + DE group was upregulated 2.9275fold compared to the expression in inactive pterygium tissues ( $p<0.0001$; Fig. 5). VEGF mRNA expression obviously upregulated in active + DE group versus active $-\mathrm{DE}$ group ( $p<0.0001$; Fig. 5).

\section{Correlations between the Expressions of Tear}

Inflammatory Cytokines and Clinical Features

In the Pteg + DE patients, the severity of dry eye positively correlated with the tear IL-6 concentration; further, pterygium activity positively correlated with tear VEGF, FGF2, MMP-1, and MMP-9 concentrations (Table 4).

The Key Role of VEGF in Cross Talk between Pterygium and Dry Eye

\section{Discussion}

Inflammation Is an Important Reason for the High Incidence of the Coexistence of Pterygium and Dry Eye In this study, the rate of combined dry eye among 103 patients with primary pterygium reached $73.8 \%$, which is higher than the incidence of dry eye in the general population [31]. What are the possible reasons for this? The environmental factors that cause pterygium (such as UV radiation) can disrupt ocular surface homeostasis and directly cause dry eye. Pterygium can also directly affect ocular surface regularity to reduce tear film stability. For dry eye patients with abnormal tear film, the loss of the protective function of the ocular surface further promoted the occurrence and development of pterygium. A re- 


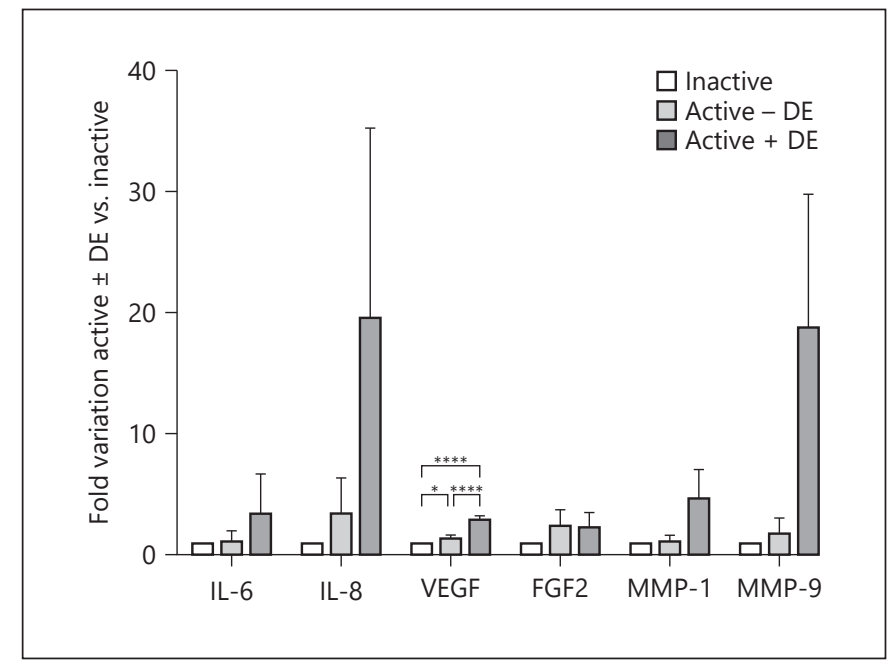

Fig. 5. Bar graph showing the mRNA expression of cytokines in samples of active pterygium with and without dry eye vs. the mRNA expression in samples of inactive pterygium. All values were obtained by real-time polymerase chain reaction and are reported as fold variations over control obtained from specimens of inactive pterygium. Cytokine mRNA expression levels in pterygium tissue were compared between 2 groups using the KruskalWallis test. ${ }^{*} p<0.05 ;{ }^{* * * *} p<0.0001$.

cent study focusing on dry eye severity in recurrent pterygium indicated a high prevalence of dry eye in patients with primary and recurrent pterygium; thus, dry eye could be a risk factor for pterygium recurrence via ocular surface inflammation [4]. However, the study did not demonstrate the mechanisms or core factors of inflammation. In contrast, the present study confirmed that proinflammatory factors, matrix metalloproteases, and growth factors were all involved in the occurrence and development of dry eye and pterygium and included IL-6, IL-8, MMP-1, MMP-9, VEGF, and bFGF. The results showed that the concentrations of tear IL-6, IL-8, and MMP-9 in simple pterygium patients and simple dry eye patients were all significantly higher than in normal individuals, whereas the concentrations of tear IL-6, IL-8, VEGF, MMP-1, and MMP-9 were similar between simple pterygium patients and simple dry eye patients. These findings confirm the hypothesis that dry eye and pterygium have similar inflammation profiles, and that the 2 conditions are interlinked. Tear concentrations of VEGF and MMP-9 in Pteg + DE patients were significantly higher than in patients in Pteg - DE groups, and tear concentrations of VEGF, bFGF, MMP-1, and MMP-9 in Pteg + DE patients were significantly higher than in patients
Table 4. Spearman's correlation coefficients for the cytokine level and dry eye severity and growth activity of pterygium in pterygium patients with dry eye

\begin{tabular}{llllll}
\hline Cytokine & \multicolumn{2}{l}{ Dry eye severity } & & \multicolumn{2}{l}{$\begin{array}{l}\text { Growth activity of } \\
\text { pterygium }\end{array}$} \\
\cline { 2 - 3 } \cline { 5 - 6 } & $\rho$ & $p$ value & & $\rho$ & $p$ value \\
\hline IL-6 & 0.290 & $0.011^{*}$ & & 0.146 & 0.21 \\
IL-8 & 0.052 & 0.655 & & 0.222 & 0.054 \\
VEGF & 0.191 & 0.098 & & 0.436 & $0.001^{* * *}$ \\
FGF2 & 0.153 & 0.187 & & 0.271 & $0.018^{*}$ \\
MMP-1 & 0.208 & 0.072 & & 0.325 & $0.004^{* *}$ \\
MMP-9 & 0.155 & 0.182 & & 0.348 & $0.002^{* *}$ \\
\hline
\end{tabular}

MMP, matrix metalloproteinase; IL, interleukin; VEGF, vascular endothelial growth factor; bFGF, fibroblast growth factor 2 (basic).

Correlations between the expressions of tear inflammatory cytokines and dry eye severity: the severity of dry eye positively correlated with the tear IL-6 concentration $\left(r=0.290, p<0.05^{*}\right)$. Correlations between the expressions of tear inflammatory cytokines and pterygium activity: pterygium activity positively correlated with tear VEGF $\left(r=0.436,{ }^{* * *} p<0.001\right)$, FGF2 $(r=$ $\left.0.271,{ }^{* *} p<0.01\right)$, MMP-1 $(r=0.325, * p<0.05)$, and MMP-9 $\left(r=0.348,{ }^{* *} p<0.01\right)$ concentrations.

in DE groups, indicating that the coexistence of these 2 diseases might aggravate ocular surface inflammation; further, aggravated inflammation results in the mutual promotion of these 2 diseases. Therefore, inflammation is an important pathological factor in the high incidence of the coexistence of pterygium and dry eye.

\section{Pterygium-Derived Inflammation Can Cause Dry Eye} and Promote Dry Eye Severity

The correlation analysis of Pteg + DE patients showed that the severity of dry eye was positively correlated with pterygium activity and pterygium disease course. When the pterygium disease course was prolonged, the growth of pterygium was found to be more active, the congestion more severe, and the dry eye more severe. Further regression analysis showed that out of the 2 factors-pterygium disease course and activity-only pterygium activity was a significant predictor of the severity of dry eye in pterygium patients. Therefore, pterygium patients were divided into the inactive pterygium and active pterygium subgroups to further analyze the pathological roles of inflammatory factors and their clinical correlations. The results showed that the expression levels of certain proteins significantly correlated with pterygium activity. The expres- 
sion levels of IL-8, VEGF, MMP-1, and MMP-9 were significantly higher in active Pteg patients than in inactive Pteg patients (Fig. 3); further, the VEGF mRNA levels in active Pteg tissues were upregulated relative to inactive Pteg patients (Fig. 5). These results suggested that active pterygium could produce higher concentrations of inflammatory factors (including in tears and pterygium tissues), and their persistent presence might promote the occurrence and development of dry eye. Surgical treatment should be administered in a timely manner for active pterygium in order to reduce the aggravation of dry eye caused by tear inflammatory factors.

Angiogenesis and inflammation are 2 mutually influencing pathophysiological processes [32], and VEGF is a cross talk promoter for both [33]. VEGF is an important factor in angiogenesis in pterygium, but it can also increase vascular endothelial permeability and promote corneal lymphangiogenesis, expanding inflammatory reactions [24]. Jiang et al. [8] showed that VEGF expression was increased in the tears of dry eye patients, and the subconjunctival injection of bevacizumab (anti-VEGF) could relieve ocular surface inflammation, which was consistent with the present study results. This study found that tear VEGF concentration in patients with active pterygium combined with dry eye was almost twice that of patients with simple active pterygium. VEGF expression in active + DE pterygium tissues was upregulated compared with the expression in active-DE pterygium tissues. In addition, tear VEGF concentration in active pterygium patients positively correlated with pterygium activity.

These results indicated that tear VEGF might originate in pterygium tissues; when congestion in pterygium was severe, VEGF expression and vascular permeability might be higher, promoting the occurrence and development of ocular surface inflammation and aggravating dry eye. These results also suggested that VEGF was one of the key factors promoting dry eye in inflamed tissues in pterygi$\mathrm{um}$, and perioperative anti-VEGF treatment might be effective. In particular, perioperative anti-VEGF treatment must be used cautiously for pterygium resection combined with autoconjunctival graft, as graft vascularization may be compromised [34].

Overall, the present results suggest that the persistent presence of pterygium might aggravate dry eye; further, pterygium activity and its produced inflammatory factors such as VEGF could aggravate dry eye. These results suggest that researchers should pay attention to the ocular surface damage caused by pterygium inflammation. This is in contrast with the previous viewpoint that used pterygium length into the transparent cornea as the criterion

The Key Role of VEGF in Cross Talk between Pterygium and Dry Eye for surgery. The timely resection of pterygium, especially active pterygium, should be promoted to prevent damage to the ocular surface caused by cytokines from pterygium and its possible cause or aggravate dry eye. Of course, even though in some cases pterygium disease course is long, pterygium can still be inactive; therefore, its influence on dry eye should be specially evaluated and cannot be generalized. There are other ways to reduce ocular surface damage caused by both dry eye and pterygium inflammation, such as the use of topical cyclosporine A [35] or glucocorticoid eye drops [36] rather than advocating for surgery with potential complications.

\section{VEGF Is a Core Factor in the Cross Talk between Pterygium and Dry Eye}

UV radiation-induced stress and tear hyperosmolarity are important factors in the pathogenicity of pterygium and dry eye; they are also 2 major stimulants of the NF- $\kappa B$ signaling pathway. The NF- $\mathrm{KB}$ signaling pathway participates in the pathophysiological processes related to these 2 diseases via cellular processes such as inflammation, angiogenesis, and matrix remodeling [24]. Thus, the NF- $\kappa B$ signaling pathway and related cytokines may play important roles in the cross talk between pterygium and dry eye.

The NF- $\kappa B$ signaling pathway activates IL- 6 expression [37]. As a marker for ocular surface inflammation, it can directly or indirectly damage the ocular surface epithelium and mucin, thereby participating in the pathological process of dry eye [38]. This study showed that tear IL-6 concentration was significantly higher in Pteg + DE patients than in Pteg - DE patients. Tear IL- 6 concentration was positively correlated with the severity of the dry eye $(r=0.290, p=0.011)$, and the IL-6 expression level in both tears and pterygium tissues were similar between the active Pteg group and the inactive Pteg group. These results suggest that high levels of tear IL-6 expression are not directly correlated with pterygium activity, which might be due to the participation of inflammation in the pathological process of dry eye. Tear IL- 6 might become a biomarker for determining the severity of dry eye.

Watari et al. [39] reported that activation of the NF- $\mathrm{kB}$ signaling pathway upregulated VEGF in a mouse model; in turn, VEGF activates the NF- $\kappa \mathrm{B}$ signaling pathway [40]. DeNiro and Al-Mohanna [41] further showed that activation of the NF- $\kappa B$ signaling pathway by VEGF upregulated MMP-9. The present study showed that the tear MMP-9 concentration was significantly higher in active Pteg patients than in inactive Pteg patients and was positively correlated with pterygium activity. These findings indicate that the inflammation from pterygium might ac- 
tivate the NF- $\kappa B$ signaling pathway through high VEGF expression, thus regulating the expression of ocular surface MMP-9.

MMP-9 can disrupt the corneal epithelial basement membrane and the tight junctions between epithelial cells to affect the corneal epithelial barrier and cause corneal epithelial defects and ocular irritation symptoms [42]. The function of MMP-9 in the onset of dry eye has received a great deal of attention [43], and researchers have proposed that MMP-9 might become a diagnostic marker of dry eye at the molecular level [44]. Recently, a study inhibited MMP-9 as a new target for dry eye treatment [45]. In addition, MMP-9 plays important roles in the onset of pterygium, it not only disrupts the epithelial barrier to facilitate the invasion of pterygium into a transparent cornea, but also promotes the development and postoperative recurrence of pterygium $[7,21]$. MMPs play important roles in the regulation of angiogenesis, and they can upregulate VEGF to promote angiogenesis [46]. The present study confirmed that, among the active Pteg patients, the MMP9 expression levels in tears and pterygium tissues were significantly higher in the presence of dry eye than in the absence of dry eye. These results indicate that MMP-9 is associated with not only inflammation in pterygium but also inflammation in dry eye. One possible reason for this is that the high osmotic status of dry eye can activate the NF- $\kappa B$ signaling pathway to upregulate MMP-9 expression, and high osmotic status has a positive feedback relationship with VEGF and MMP-7 under pathological conditions. VEGF and MMP-9 can both recruit inflammatory cells to the corneal stroma. MMP-9 is both an upstream activator and a downstream target of VEGF [47].

The above results suggest that the positive feedback regulation between MMP-9 and VEGF plays important roles in the cross talk between pterygium and dry eye. In particular, VEGF can both activate the NF- $\kappa B$ signaling pathway to upregulate MMP-9 expression and act as a target of the NF- $\kappa B$ signaling pathway; therefore, it may play a key role in the cross talk between pterygium and dry eye. Treatments targeting VEGF might improve the efficacy of treating the coexistence of these 2 diseases.

In summary, these findings may improve researchers' understanding of the mechanism of interaction between dry eye and pterygium. In addition to the disruption of ocular surface regularity and the dysfunction of the tear film, the high incidence of the coexistence of dry eye and pterygium and their interactive influence are associated with ocular surface inflammation. These diseases have a similar inflammatory pathway, and VEGF may be the core factor in this cross talk.

Clinically, pterygium with dry eye should be treated quickly and concomitantly. Firstly, both pterygium activity and dry eye severity should be evaluated in pterygium patients. Secondly, for patients with combined pterygium and dry eye, standard and active dry eye treatment should be effective to control pterygium progression. Thirdly, pterygium resection done in a timely manner should reduce the tear inflammatory factors in dry eye and improve the efficacy of dry eye treatment.

\section{Statement of Ethics}

The Ethics Committee of Zhongshan Ophthalmic Center, Sun Yat-sen University, approved this cross-sectional study; it conformed to the ethical guidelines of the Helsinki Declaration. All of the experimental subjects filled out an informed consent form before participating in the study.

\section{Disclosure Statement}

The authors have no conflicts of interest to declare.

\section{Funding Sources}

This work was supported by the Provincial frontier and key technology innovation special fund of Guangdong Province (2015B020227001), Science and Technology Program of Guangzhou (15020083), Provincial scientific medical technology research fund of Guangdong Province (A2017487), and Provincial nature science foundation of Guangdong Province (2018A030313095).

References

Ophthalmic Res 2020;63:320-331 DOI: $10.1159 / 000503636$
Liu/Song/Wang/Lai/Li/Wan/Xu/Huang/ Liu/Wang
1 Lee AJ, Lee J, Saw SM, Gazzard G, Koh D, Widjaja D, et al. Prevalence and risk factors associated with dry eye symptoms: a population based study in Indonesia. Br J Ophthalmol. 2002 Dec;86(12):1347-51.

2 Li M, Zhang M, Lin Y, Xiao Q, Zhu X, Song S, et al. Tear function and goblet cell density after pterygium excision. Eye (Lond). $2007 \mathrm{Feb}$; 21(2):224-8.

3 Goldberg L, David R. Pterygium and its relationship to the dry eye in the Bantu. Br J Ophthalmol. 1976 Oct;60(10):720-1.

4 Tan J, Vollmer-Conna U, Tat L, Coroneo M. Dry-Eye Disease in Recurrent Pterygium. Ophthalmic Res. 2019;61(4):199-203.

5 Baudouin C, Aragona P, Messmer EM, Tomlinson A, Calonge M, Boboridis KG, et al. Role of hyperosmolarity in the pathogenesis and management of dry eye disease: proceedings of the OCEAN group meeting. Ocul Surf. 2013 Oct;11(4):246-58. 
6 Di Girolamo N, Chui J, Coroneo MT, Wakefield D. Pathogenesis of pterygia: role of cytokines, growth factors, and matrix metalloproteinases. Prog Retin Eye Res. 2004 Mar;23(2): 195-228.

7 Dushku N, John MK, Schultz GS, Reid TW. Pterygia pathogenesis: corneal invasion by matrix metalloproteinase expressing altered limbal epithelial basal cells. Arch Ophthalmol. 2001 May;119(5):695-706.

8 Jiang X, Lv H, Qiu W, Liu Z, Li X, Wang W. Efficiency and safety of subconjunctival injection of anti-VEGF agent - bevacizumab - in treating dry eye. Drug Des Devel Ther. 2015 Jun;9:3043-50.

9 Beden U, Irkeç M, Orhan D, Orhan M. The roles of T-lymphocyte subpopulations (CD4 and CD8), intercellular adhesion molecule-1 (ICAM-1), HLA-DR receptor, and mast cells in etiopathogenesis of pterygium. Ocul Immunol Inflamm. 2003 Jun;11(2):115-22.

10 Stern ME, Gao J, Schwalb TA, Ngo M, Tieu DD, Chan CC, et al. Conjunctival T-cell subpopulations in Sjögren's and non-Sjögren's patients with dry eye. Invest Ophthalmol Vis Sci. 2002 Aug;43(8):2609-14.

11 Wei Y, Asbell PA. The core mechanism of dry eye disease is inflammation. Eye Contact Lens. 2014 Jul;40(4):248-56.

12 Huang Y, He H, Sheha H, Tseng SC. Ocular demodicosis as a risk factor of pterygium recurrence. Ophthalmology. 2013 Jul;120(7) $1341-7$.

13 The definition and classification of dry eye disease: report of the Definition and Classification Subcommittee of the International Dry Eye WorkShop (2007). Ocul Surf. 2007 Apr; 5(2):75-92.

14 Ozsutcu M, Arslan B, Erdur SK, Gulkilik G, Kocabora SM, Muftuoglu O. Tear osmolarity and tear film parameters in patients with unilateral pterygium. Cornea. 2014 Nov;33(11): 1174-8.

15 Hill JC, Maske R. Pathogenesis of pterygium. Eye (Lond). 1989;3(Pt 2):218-26.

16 Di Girolamo N, Wakefield D, Coroneo MT. UVB-mediated induction of cytokines and growth factors in pterygium epithelial cells involves cell surface receptors and intracellular signaling. Invest Ophthalmol Vis Sci. 2006 Jun;47(6):2430-7.

17 Di Girolamo N, Kumar RK, Coroneo MT, Wakefield D. UVB-mediated induction of interleukin- 6 and -8 in pterygia and cultured human pterygium epithelial cells. Invest Ophthalmol Vis Sci. 2002 Nov;43(11):3430-7.

18 Alexander G, Carlsen H, Blomhoff R. Corneal NF-kappaB activity is necessary for the retention of transparency in the cornea of UV$\mathrm{B}$-exposed transgenic reporter mice. Exp Eye Res. 2006 Apr;82(4):700-9.

19 Chui J, Di Girolamo N, Wakefield D, Coroneo MT. The pathogenesis of pterygium: current concepts and their therapeutic implications. Ocul Surf. 2008 Jan;6(1):24-43

20 Di Girolamo N, Wakefield D, Coroneo MT. Differential expression of matrix metallopro- teinases and their tissue inhibitors at the advancing pterygium head. Invest Ophthalmol Vis Sci. 2000 Dec;41(13):4142-9.

21 Li DQ, Lee SB, Gunja-Smith Z, Liu Y, Solomon A, Meller D, et al. Overexpression of collagenase (MMP-1) and stromelysin (MMP-3) by pterygium head fibroblasts. Arch Ophthalmol. 2001 Jan;119(1):71-80.

22 Jin J, Guan M, Sima J, Gao G, Zhang M, Liu $Z$, et al. Decreased pigment epithelium-derived factor and increased vascular endothelial growth factor levels in pterygia. Cornea. 2003 Jul;22(5):473-7.

23 Powers MR, Qu Z, O'Brien B, Wilson DJ, Thompson JE, Rosenbaum JT. Immunolocalization of bFGF in pterygia: association with mast cells. Cornea. 1997 Sep;16(5):545-9.

24 Lan W, Petznick A, Heryati S, Rifada M, Tong L. Nuclear Factor- $\kappa B$ : central regulator in ocular surface inflammation and diseases. Ocul Surf. 2012 Jul;10(3):137-48.

25 Schiffman RM, Christianson MD, Jacobsen G, Hirsch JD, Reis BL. Reliability and validity of the Ocular Surface Disease Index. Arch Ophthalmol. 2000 May;118(5):615-21.

26 Toda I, Fujishima H, Tsubota K. Ocular fatigue is the major symptom of dry eye. Acta Ophthalmol (Copenh). 1993 Jun;71(3):347-52.

27 Bron AJ, Evans VE, Smith JA. Grading of corneal and conjunctival staining in the context of other dry eye tests. Cornea. 2003 Oct;22(7): $640-50$.

28 Taylor HR, West SK, Rosenthal FS, Munoz B, Newland HS, Emmett EA. Corneal changes associated with chronic UV irradiation. Arch Ophthalmol. 1989 Oct;107(10):1481-4.

29 Tan DT, Chee SP, Dear KB, Lim AS. Effect of pterygium morphology on pterygium recurrence in a controlled trial comparing conjunctival autografting with bare sclera excision. Arch Ophthalmol. 1997 Oct;115(10): 1235-40.

30 Methodologies to diagnose and monitor dry eye disease: report of the Diagnostic Methodology Subcommittee of the International Dry Eye WorkShop (2007). Ocul Surf. 2007 Apr; 5(2):108-52.

31 The epidemiology of dry eye disease: report of the Epidemiology Subcommittee of the International Dry Eye WorkShop (2007). Ocul Surf. 2007 Apr;5(2):93-107.

32 Yan ZX, Luo Y, Liu NF. Blockade of angiopoietin-2/Tie2 signaling pathway specifically promotes inflammation-induced angiogenesis in mouse cornea. Int J Ophthalmol. 2017 Aug;10(8):1187-94.

33 Ferrara N, Gerber HP, LeCouter J. The biology of VEGF and its receptors. Nat Med. 2003 Jun;9(6):669-76.

34 Tan JC, Kuo MX, Coroneo MT. Autoconjunctival Graft Compromise After Pterygium Surgery in a Patient Receiving Intravitreal Anti-Vascular Endothelial Growth Factor Injections. Cornea. 2016 Dec;35(12):1653-5.

35 Gum SI, Kim YH, Jung JC, Kim IG, Lee JS, Lee $\mathrm{KW}$, et al. Cyclosporine A inhibits TGF- $\beta 2$ induced myofibroblasts of primary cultured human pterygium fibroblasts. Biochem Biophys Res Commun. 2017 Jan;482(4):1148-53.

36 Frucht-Pery J, Siganos CS, Solomon A, Shvartzenberg T, Richard C, Trinquand C. Topical indomethacin solution versus dexamethasone solution for treatment of inflamed pterygium and pinguecula: a prospective randomized clinical study. Am J Ophthalmol. $1999 \mathrm{Feb} ; 127(2): 148-52$.

37 Takahra T, Smart DE, Oakley F, Mann DA. Induction of myofibroblast MMP-9 transcription in three-dimensional collagen I gel cultures: regulation by NF-kappaB, AP-1 and Sp1. Int J Biochem Cell Biol. 2004 Feb;36(2):353-63.

38 Higuchi A, Kawakita T, Tsubota K. IL-6 induction in desiccated corneal epithelium in vitro and in vivo. Mol Vis. 2011;17:2400-6.

39 Watari K, Nakao S, Fotovati A, Basaki Y, Hosoi F, Bereczky B, et al. Role of macrophages in inflammatory lymphangiogenesis: enhanced production of vascular endothelial growth factor C and D through NF-kappaB activation. Biochem Biophys Res Commun. 2008 Dec;377(3):826-31.

40 Marumo T, Schini-Kerth VB, Busse R. Vascular endothelial growth factor activates nuclear factor-kappaB and induces monocyte chemoattractant protein-1 in bovine retinal endothelial cells. Diabetes. 1999 May;48(5): 1131-7.

41 DeNiro M, Al-Mohanna FA. Nuclear factor kappa-B signaling is integral to ocular neovascularization in ischemia-independent microenvironment. PLoS One. 2014 Jul;9(7): e101602.

42 Pflugfelder SC, Farley W, Luo L, Chen LZ, de Paiva CS, Olmos LC, et al. Matrix metalloproteinase-9 knockout confers resistance to corneal epithelial barrier disruption in experimental dry eye. Am J Pathol. 2005 Jan;166(1):61-71.

43 Chotikavanich S, de Paiva CS, Li Q, Chen JJ, Bian F, Farley WJ, et al. Production and activity of matrix metalloproteinase- 9 on the ocular surface increase in dysfunctional tear syndrome. Invest Ophthalmol Vis Sci. 2009 Jul; 50(7):3203-9.

44 Sambursky R, Davitt WF 3rd, Latkany R, Tauber S, Starr C, Friedberg M, et al. Sensitivity and specificity of a point-of-care matrix metalloproteinase 9 immunoassay for diagnosing inflammation related to dry eye. JAMA Ophthalmol. 2013 Jan;131(1):24-8.

45 Mori M, De Lorenzo E, Torre E, Fragai M, Nativi $C$, Luchinat $C$, et al. A highly soluble matrix metalloproteinase-9 inhibitor for potential treatment of dry eye syndrome. Basic Clin Pharmacol Toxicol. 2012 Nov;111(5):289-95.

46 Bergers G, Brekken R, McMahon G, Vu TH, Itoh T, Tamaki K, et al. Matrix metalloproteinase- 9 triggers the angiogenic switch during carcinogenesis. Nat Cell Biol. 2000 Oct; 2(10):737-44.

47 Hollborn M, Stathopoulos C, Steffen A, Wiedemann P, Kohen L, Bringmann A. Positive feedback regulation between MMP-9 and VEGF in human RPE cells. Invest Ophthalmol Vis Sci. 2007 Sep;48(9):4360-7.
The Key Role of VEGF in Cross Talk between Pterygium and Dry Eye
Ophthalmic Res 2020;63:320-331 DOI: $10.1159 / 000503636$ 